\title{
Redes neurais aplicadas na redução de ruído impulsivo de imagens digitais
}

\author{
Pablo Luiz Braga Soares ${ }^{1}$ \\ José Patrocínio da Silva ${ }^{1}$
}

\begin{abstract}
Resumo: Este trabalho propõe a utilização de um novo método para detecção e remoção de ruído impulsivo de imagens digitais, baseado na combinação de duas redes neurais artificiais (RNA). O algoritmo de treinamento das RNA baseia-se na técnica da retropropagação do erro (algoritmo backpropagation). A primeira RNA é utilizada para detecção do ruído, conhecido como sal e pimenta, e a segunda RNA é utilizada para substituir tal ruído por um valor estimado. O método proposto é comparado com outros métodos da literatura em termos de julgamento visual, tempo computacional e também usando a medida quantitativa Mean Square Error (MSE). Os resultados obtidos mostram um bom desempenho do método aplicado. Em termos numéricos foi obtido um MSE menor quando comparado com os métodos mais usados e publicados na literatura. Visualmente, obteve-se uma maior redução nos níveis de ruído, o que possibilitou uma melhor visualização das imagens analisadas.
\end{abstract}

Palavras-chave: Detector de ruído. Estimador de ruído. Imagens digitais. Redes neurais artificiais. Ruído impulsivo.

\begin{abstract}
This paper proposes the use of a new method to detect and remove impulsive noise from digital images, based on the combination of the two artificial neural networks (ANN). The ANN training algorithm is based on the backpropagation technique. The first ANN is used to detect the impulsive noise, known as salt and pepper, and the second ANN is used to remove it using an estimated value. The proposed method is compared with others previously presented by the literature, in order to judge the visual aspect, evaluate the computational time and apply a quantitative measure, MSE - Mean Square Error. The results show a good performance of the applied method. Numerically, was obtained a lower MSE, when compared with the most commonly used reported in the literature. Visually, we obtained a reduction in noise levels, permitting a better visualization of the analyzed image.
\end{abstract}

Keywords: Artificial neural networks. Digital images. Impulse detector. Impulse estimator. Impulse noise.

\section{Introdução}

Algoritmos de processamento de imagens, tais como os de seleção e reconhecimento de características, dependem do desempenho de um filtro de remoção de ruído impulsivo de imagens. O ruído impulsivo, ou ruído sal e pimenta, em imagens digitais, é geralmente proveniente do processo de transmissão de dados [1]. Imagens são frequentemente corrompidas por ruído impulsivo no momento em que são capturadas ou quando estão sendo transmitidas por algum tipo de canal de dados. Existem aplicações, tais como detecção de borda em imagens, em que se faz necessário a remoção de ruído para que se possa observar detalhes mínimos de identificação de cada imagem. O objetivo principal de um algoritmo de remoção, ou filtro, é remover o ruído da imagem preservando os detalhes finos como as bordas.

\footnotetext{
${ }^{1}$ Mestre em Ciência da Computação, UERN/UFEFRSA, Campus 1 - BR 110 - Mossoró (RN) - Brasil

\{pabloufersa@gmail.com\}, \{patroc@ufersa.edu.br\}
}

http://dx.doi.org/10.5335/rbca.2013.2454 
Diferentes algoritmos têm sido propostos para remover o ruído impulsivo. Dentre os algoritmos mais utilizados estão o filtro da mediana [2], o filtro da mediana adaptativo [2]-[7], [8], as técnicas fuzzy [9], o operador laplaciano [10] e os métodos que se baseiam em treinamentos prévios [6]. Outros métodos existentes utilizam um detector de ruído impulsivo para determinar se um pixel deve ou não ser modificado e em seguida o filtro é aplicado somente nos pixels identificados como ruidosos. Esse processo é conhecido como técnica de comutação e apresenta a vantagem de ser simples e ainda mais eficaz do que os métodos uniformemente aplicados [8].

Recentemente, um filtro detector de ruído impulsivo, conhecido por diferenças absolutas ordenada por rank, do inglês Rank-Ordered Absolute Differences (ROAD), foi proposto em Garnett, Huegerich e Chui [11]. Esse detector considera que para um valor de ROAD entre 60 - 255, o pixel representa um ruído, e para ROAD abaixo de 60, o pixel não é considerado como ruído.

Nos últimos anos, técnicas avançadas, baseadas em métodos computacionais, têm sido aplicadas para filtragem de imagens, abordando o problema de forma não linear. Dessa forma, as redes neurais artificiais (RNA) podem ser potencialmente aplicadas, devido seu desempenho na solução de problemas envolvendo processamento de imagens. Recentemente, Kaliraj e Baskar [12] utilizaram RNA como ferramenta de detecção de ruído. Porém, para removê-los, utilizaram dois algoritmos baseados na mediana como forma de estimar o valor do pixel ruidoso.

Neste trabalho, um novo método para detecção e remoção de ruído impulsivo, baseado na junção de duas RNA, é proposto. A primeira RNA é utilizada como detector de ruído, como em Kaliraj e Baskar [12] e a segunda é utilizada como estimador de um novo valor para o pixel ruidoso, reduzindo o ruído presente na imagem original. Os resultados obtidos através do método proposto neste trabalho são comparados com resultados publicados na literatura, considerando o mesmo tipo de abordagem [13], [14].

O artigo está dividido como segue: na seção 2 apresentamos o esquema do método proposto, bem como os detalhes de sua implementação e uma breve descrição sobre ruído impulsivo. Na seção 3 os resultados simulados são apresentados e, finalmente, na seção 4, são apresentadas as principais conclusões da pesquisa.

\section{Definição do método proposto}

O método aplicado neste trabalho está baseado em duas fases. Cada fase é processada por uma rede neural artificial, referenciada neste trabalho como RNA-1 e RNA-2. A primeira fase funciona como detector de ruído impulsivo, usando uma imagem artificial para treinamento da primeira (RNA-1), detalhada na seção 2.1. Na segunda fase, o valor do novo pixel é estimado usando os valores dos pixels vizinhos como entrada para uma segunda (RNA-2). O esquema geral é mostrado na Figura 1.

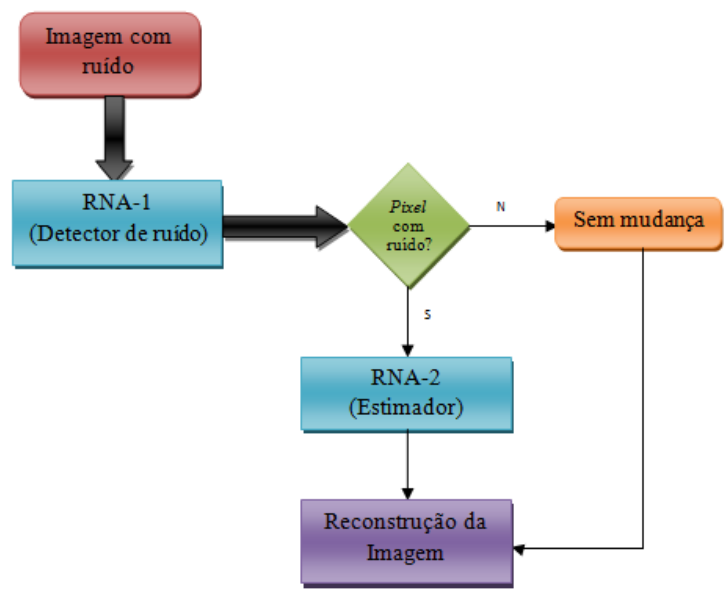

Figura 1: Esquema geral do método proposto 


\subsection{Ruído impulsivo (sal e pimenta)}

Por definição, considera-se ruído qualquer tipo de informação indesejada que obstrui a aquisição e o processamento da informação desejada. Existem tipos de ruídos que podem estar presentes em imagens e esses tipos podem ser determinados pelo formato do histograma do ruído [15]. Existem alguns tipos de ruído que podem ser encontrados em imagens digitais, tais como ruído distribuído uniformemente, distribuição gaussiana, distribuição exponencial negativa e ruído impulsivo. Neste trabalho, o foco está no ruído impulsivo, para maiores detalhes sobre os outros tipos de ruído ver [15]. O ruído impulsivo pode ocorrer devido a defeitos no sistema de geração de imagens. Pixels ruidosos brancos são chamados de sal e os pixels de ruído preto são chamados de pimenta. Neste trabalho, os valores de sal e pimenta são, respectivamente, 255 e 0.

Existem duas maneiras pelas quais uma imagem pode ser corrompida por ruído. A primeira é chamada ruído aditivo, na qual simplesmente é adicionado algum tipo de ruído a uma imagem até então livre de ruído. A segunda maneira é denominada ruído multiplicativo, que consiste em multiplicar cada pixel da imagem por um termo de ruído aleatório. Neste trabalho, vamos trabalhar com a primeira maneira, ou seja, nas simulações realizadas, as imagens são corrompidas por uma simulação de ruído feito em um canal de dados, onde o ruído será adicionado em termos de porcentagem nas imagens da seguinte forma:

1. escolha da imagem com a qual se deseja trabalhar;

2. em uma imagem de ordem 256 , significa que a mesma possui 65.536 pixels;

3. escolha da porcentagem de ruído impulsivo do canal, por exemplo, $30 \%$, taxa que significa que 19.661 pixels foram escolhidos aleatoriamente para serem corrompidos;

4. dos pixels escolhidos, os mesmos vão ter $50 \%$ de probabilidade de ser 0 ou 255 .

A Figura 2 ilustra a imagem de homem livre de ruído, bem como a imagem corrompida com $30 \%$ de ruído impulsivo após passar pelo canal simulado.

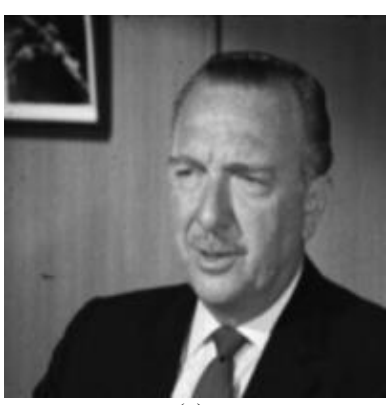

(a)

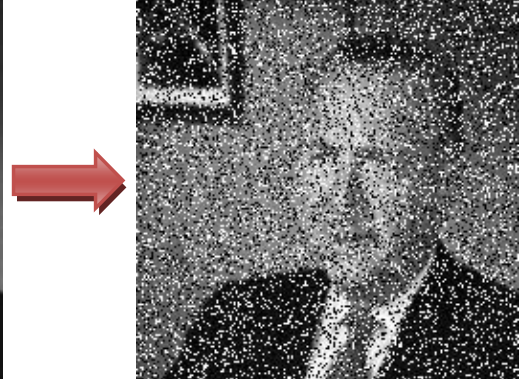

(b)

Figura 2: Homem (a) sem ruído. (b) com 30\% de ruído

\subsection{Detector de ruído}

A estrutura do detector de ruído proposto é mostrada na Figura 3 e consiste de uma rede neural Perceptron de Múltiplas Camadas (Multi Layer Perceptron - MLP), RNA-1, e um módulo de tomada de decisão. A rede neural utiliza na camada de entrada três valores obtidos por uma máscara de ordem três, mostrada na Figura 4, constituída pelo valor do pixel atual, valor da mediana e o valor do ROAD, que é considerado por Garnett, Huegerich e Chui [11] uma boa medida para avaliar pixels. A saída da rede neural é enviada para o módulo de tomada de decisão que converte o valor da saída em números binários, 1 ou 0 para verificar e classificar o estado do pixel. Ou seja, se a saída for 1, o pixel está corrompido, se for 0 , o pixel não está corrompido.

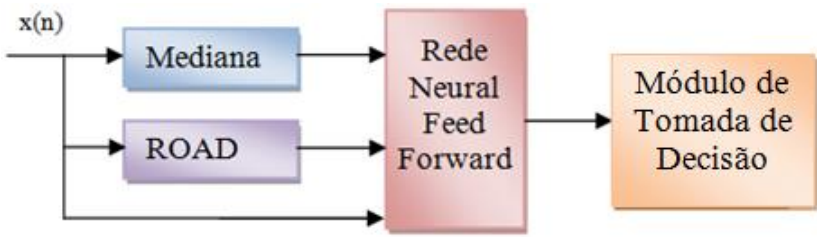

Figura 3: detector de ruído 


\begin{tabular}{|c|c|c|}
\hline$x(i-1, j-1)$ & $x(i-1, j)$ & $x(i-1, j+1)$ \\
\hline$x(i, j-1)$ & $x(i, j)$ & $x(i, j+1)$ \\
\hline$x(i+1, j-1)$ & $x(i+1, j)$ & $x(i+1, j+1)$ \\
\hline
\end{tabular}

Figura 4: elementos da janela $3 \times 3$ em torno do pixel atual

A filtragem da mediana [16] exerce importância no processamento de imagens, devido seu desempenho na retirada dos ruídos, possibilitando uma visão nítida ou quase nítida da imagem. O filtro de mediana usado no detector de ruído da Figura 3 segue o modelo padrão com janela de ordem três. A janela faz uma varredura da imagem, tomando como base $n=(i, j)$, onde $i, j$ representam as coordenadas que determinam a localização do pixel atual na janela de ordem três, aqui considerada com $W_{n}$. Desse modo tem-se:

$$
W_{n}=\{x(n+b):-1 \leq b \leq 1\}
$$

onde $x(n)$ representa o valor do pixel da imagem com ruído, $W_{n}$ constitui os elementos da janela e $b$ é o intervalo de utilização da janela. Dessa forma, o filtro da mediana é dado pela Eq. (2).

$$
m(n)=\text { mediana }\left(W_{n}\right)
$$

O valor de ROAD utilizado no detector de ruído é o mesmo proposto em Garnett, Huegerich e Chui [11] e é usado para distinguir os pixels ruidosos dos pixels não ruidosos, atribuindo um fator de ROAD alto para pixels com ruído e baixo para pixels que não apresentam ruído. Desse modo, o valor de ROAD é calculado dentro da mesma janela, da seguinte forma:

1) Cálculo da diferença absoluta entre o pixel central e os outros pixels, $d_{n}$ :

$$
d_{n}=\left|W_{n}-x(n)\right|
$$

2) Ordenação dos valores de $d_{n}$ em ordem crescente e armazenando-os na variável $r_{n}$;

$$
r_{n}=\operatorname{ordena}\left(d_{n}\right)
$$

3) Finalmente, o valor de ROAD é calculado como sendo a soma dos quatro primeiros valores de $r_{n}$.

O módulo de tomada de decisão arredonda os valores gerados da saída da RNA-1 com um limite em 0,5. Ou seja, a saída $\mathrm{y}(\mathrm{n})=0$ se a saída da RNA- $1<0,5$ e y(n) $=1$ se a saída da RNA- $1 \geq 0,5$. Dessa forma, o tomador de decisão verifica se um pixel é ruidoso ou não.

A RNA-1 utilizada no esquema da Figura 3 é, portanto, constituída de quatro camadas, sendo a camada de entrada com três neurônios, duas camadas ocultas com sete e dois neurônios respectivamente e a camada de saída com um neurônio. É importante salientar que não existe nenhum método analítico para escolher o número de camadas e neurônios ocultos de uma RNA, portanto, eles são determinados por experimentos aleatórios.

Para efeito de generalização da RNA-1, a escolha adequada das imagens de treinamento geradas artificialmente tem maior capacidade de generalização [12], [16] , [17]. Em adição, para treinamento da RNA-1 foi utilizado um conjunto de imagens mostradas na Figura 5. A imagem base é mostrada na Figura $5^{\text {a }}$. Na Figura $5 \mathrm{~b}$ tem-se a imagem base corrompida com $50 \%$ de ruído impulsivo e na Figura $5 \mathrm{c}$ tem-se a imagem desejada. A imagem base é utilizada apenas para gerar o processo de treinamento e é composta por uma matriz de ordem 100 dividida em células 2 x 2 pixels, como mostra a Figura 6, com um total de cinquenta células. Cada pixel da célula possui o mesmo nível na escala de cinza e é escolhido aleatoriamente entre os valores entre 0 e 255. 


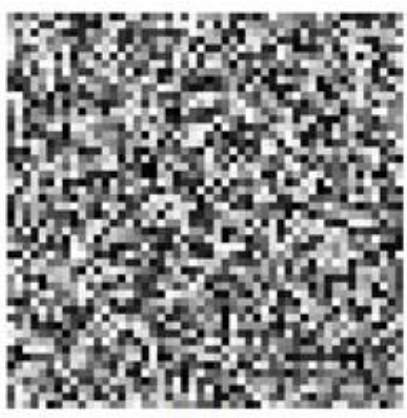

(a)

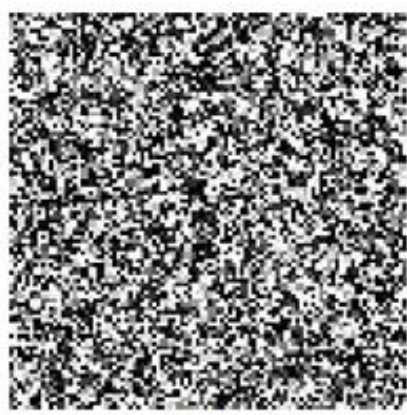

(b)

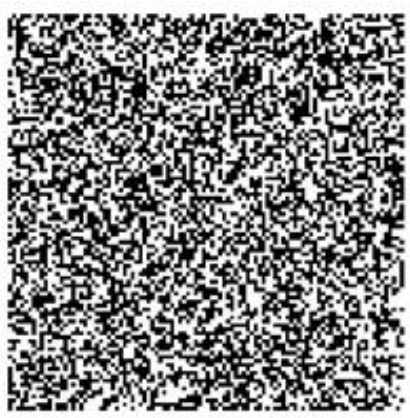

(c)

Figura 5: (a) Imagem base. (b) Imagem com 50\% de ruído. (c) Imagem alvo

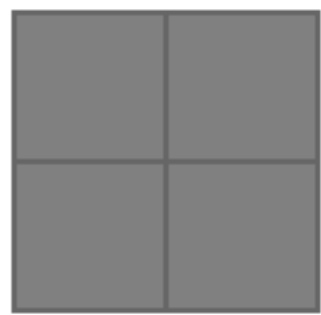

Figura 6: Exemplo de célula 2 × 2 composta de 4 pixels com mesmo nível de cinza

A rede neural é treinada usando o algoritmo backpropagation com um número máximo de 100 épocas e erro nulo. A imagem da Figura 5(b) foi digitalizada pela janela da Figura 4 e os valores da mediana, ROAD e pixel atual foram calculados para formar o conjunto de entrada para a rede neural. A saída desejada foi retirada do valor de pixel atual da imagem alvo (Figura 5(c)), que representa em pontos brancos o ruído impulsivo colocado na imagem da Figura 5(a) para transformá-lo na imagem da Figura 5(b). Cada valor de pixel compreende oito bits representados pelo nível de escala de cinza.

\subsection{Estimador de ruído}

Na segunda fase o pixel detectado como ruído é substituído por um valor calculado pelo estimador de ruído, utilizando a RNA-2. Esse método, diferentemente dos métodos tradicionais encontrados em Gabbouj, Coyle e Gallager [13], Chen e Wu [18] e Yli-Harja, Astola e Neuvo [19], mantém o valor dos pixels não corrompidos inalterados. A RNA-2 calcula o novo valor usando os pixels vizinhos ao pixel corrompido, como ilustrado na Figura 7. xC é o pixel corrompido e x1, x2, .., x8 são os vizinhos, chamados de "8-vizinhança" de $\mathrm{xC}$ [15], utilizados pela RNA-2 como entrada para calcular o novo valor de $\mathrm{xC}$.

\begin{tabular}{|c|c|c|}
\hline$x 1$ & $x 2$ & $x 3$ \\
\hline$x 4$ & $x C$ & $x 5$ \\
\hline$x 6$ & $x 7$ & $x 8$ \\
\hline
\end{tabular}

Figura 7: 8-vizinhança de $\mathrm{xC}$

Em Yildirim, Basturk e Yüksel [20] e Yüksel e Bastürk [21], para treinamento da rede neural, os autores usaram imagens artificiais iguais as que foram utilizadas na Figura 5. Porém, os autores acreditam que, com base no teorema da correlação [16], esse método não é razoável. Em Yüksel e Bastürk [22], os autores compararam o desempenho da rede neural utilizando imagens reais e artificiais para o treinamento da rede, e melhores resultados foram obtidos usando imagens reais. 
Para o treinamento da RNA-2 foram utilizadas as imagens da Figura 8, que possuem o tamanho de uma matriz de ordem 256, onde a Figura 8(b) foi obtida corrompendo a imagem da Figura 8(a) com $40 \%$ de ruído impulsivo. Os dados de entrada para a RNA-2 foram obtidos dos vizinhos do pixel considerado ruidoso da imagem da Figura 8(b) e os dados de saída da imagem da Figura 8(a).

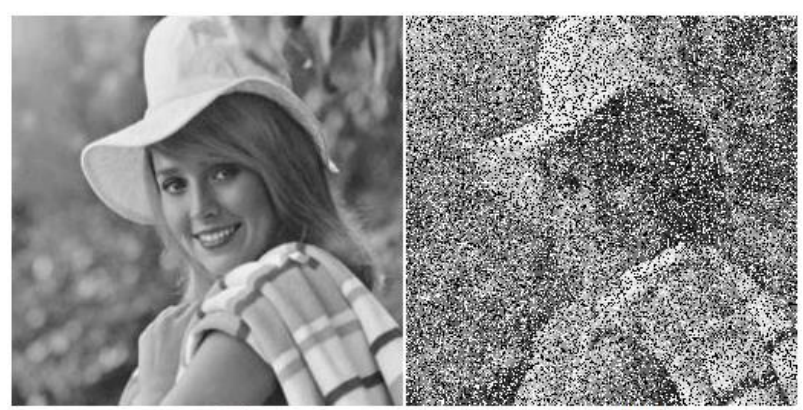

(a)

(b)

Figura 8: (a) Imagem Elaine. (b) Imagem Elaine com 40\% de ruído

A RNA-2 usada neste trabalho possui três camadas, a camada de entrada com oito neurônios que correspondem a 8-vizinhança do pixel considerado ruidoso da Figura 8(b). A camada de saída possui apenas um neurônio que corresponde ao novo valor estimado pela RNA-2. O número de 16 neurônios foi utilizado na camada oculta e esse número foi obtido por alguns experimentos. Assim, a arquitetura da RNA-2 que obteve o melhor desempenho para estimar o novo valor do pixel ruidoso apresenta a estrutura 8-16-1, conforme mostra a Figura 9. A RNA-2 foi treinada usando o algoritmo backpropagation com um número máximo de cem épocas e erro desejado de $10^{-3}$.

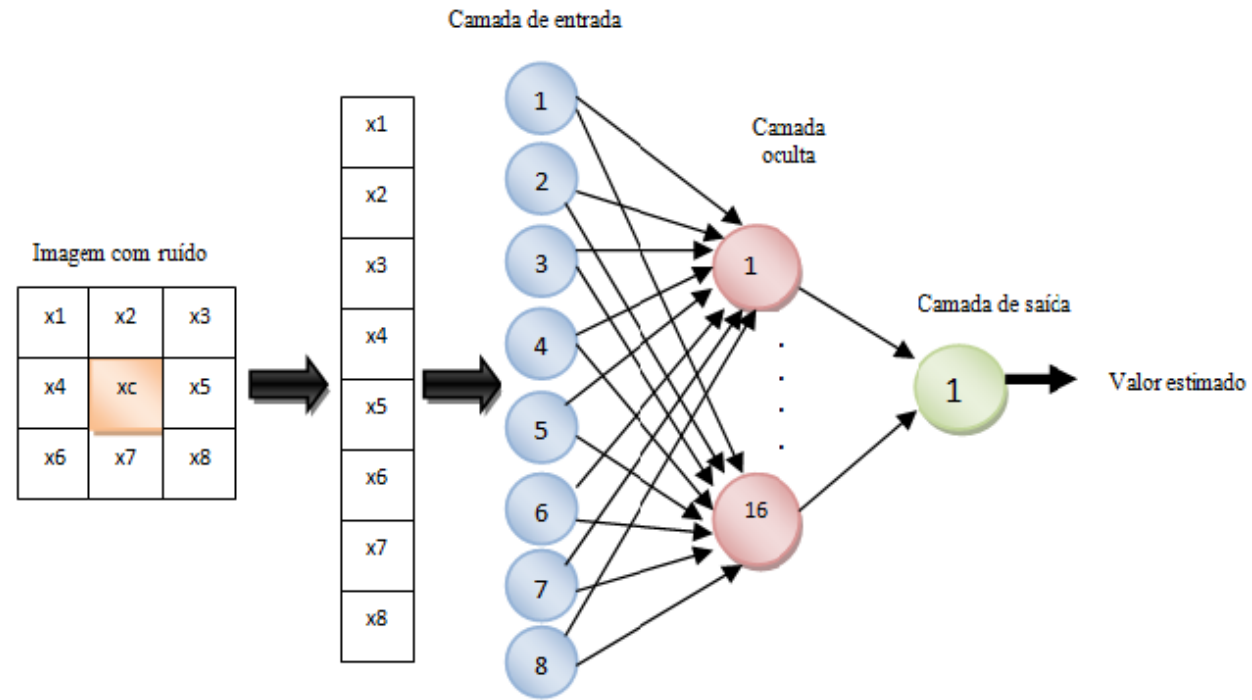

Figura 9: Estrutura do estimador de ruído (Rede neural 2) 


\section{Resultados e discussão}

Nesta seção, o desempenho do método proposto é comparado com resultados obtidos por outros métodos que propõem a redução de ruído impulsivo. As simulações foram realizadas em imagens de teste, populares da literatura, incluindo Lena, Babuíno e Pimenta [23]. Para efeito de comparação, as imagens corrompidas foram recuperadas por métodos encontrados na literatura para redução de ruído, tais como Filtro da Mediana Padrão com máscara 3 x 3 (FMP3x3), Filtro da Mediana Padrão com máscara 5 x 5 (FMP5x5) [13] e Filtro da Mediana Comutada FMC [18]. A medida quantitativa subjetiva, comparando a aplicação do método proposto com outros métodos, é mostrada de forma visual nas Figuras 10, 11 e 12, sobre as quais há que se destacar que o ruído nelas presente foi introduzido aleatoriamente com base no ruído impulsivo.

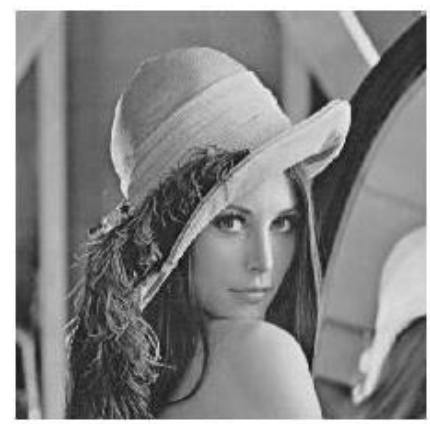

(a) Original

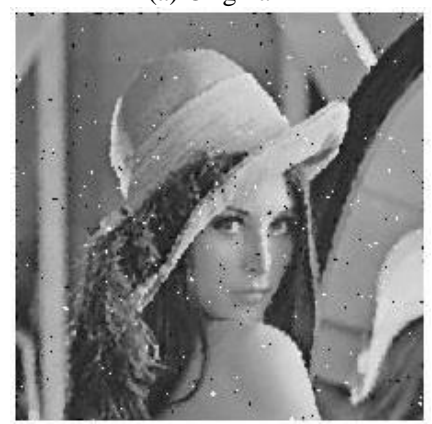

(d) FMP5x5

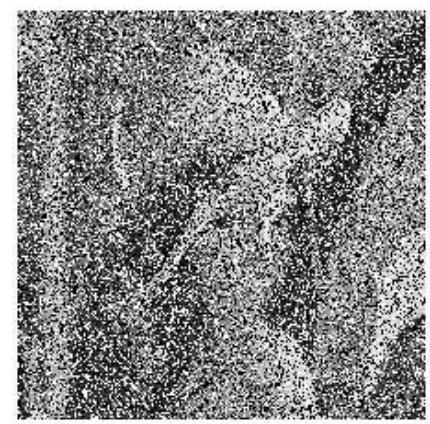

(b) Com Ruído

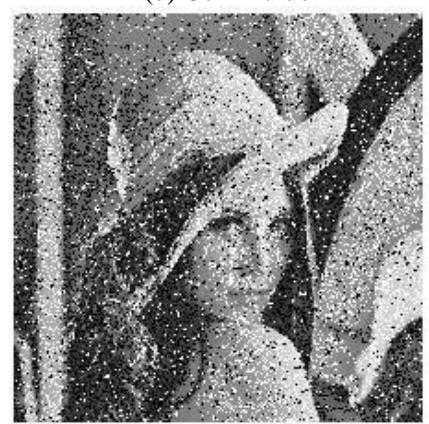

(e) FMC

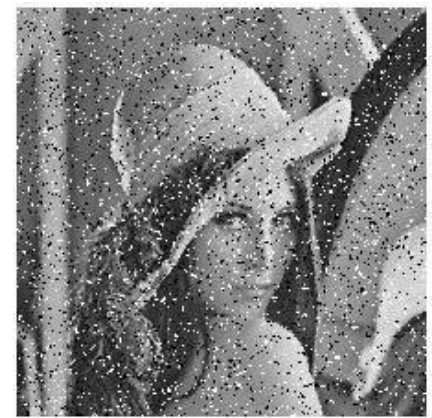

(c) FMP3x3

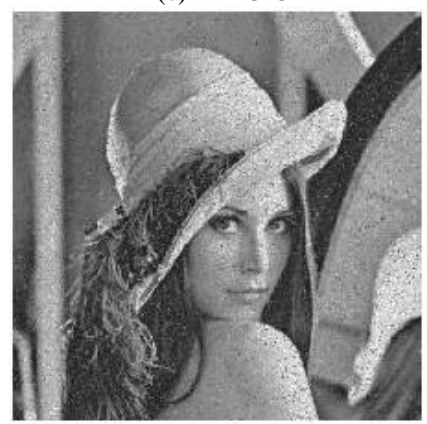

(f) Método Proposto

Figura 10: Estrutura do estimador de ruído (Rede neural 2) comparação da imagem Lena restaurada com 50\% de ruído pelos métodos. (a) Imagem Original (b) Imagem com 50\% de ruído (c) FMP3x3 (d) FMP5x5 (e) FMC (f) Método proposto.

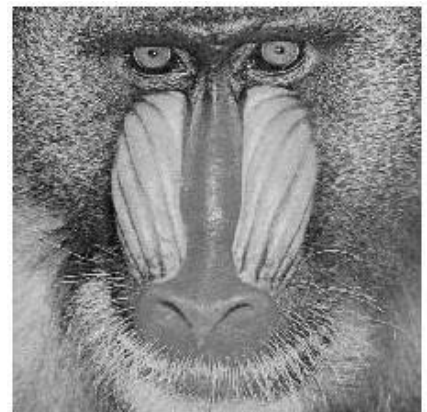

(a) Original

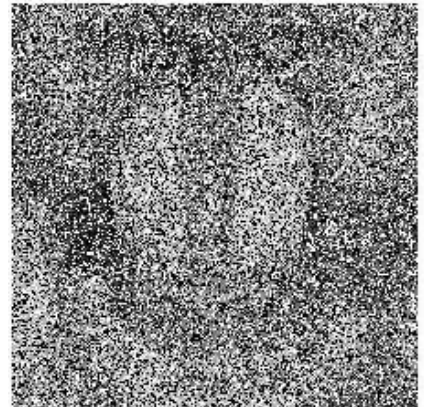

(b) Com Ruído

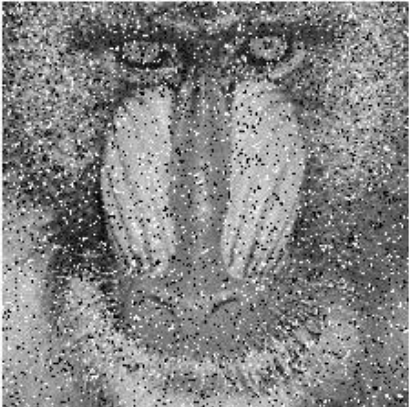

(c) FMP3x3 


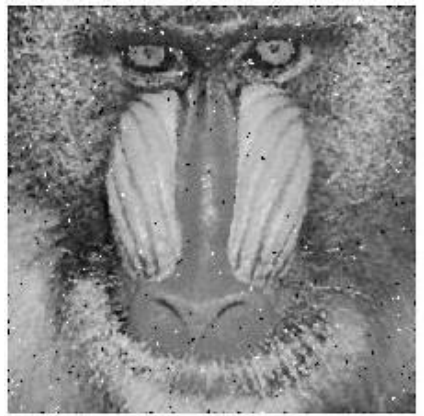

(d) FMP5x5

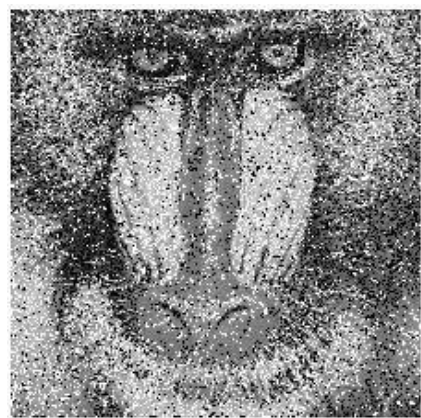

(e) FMC

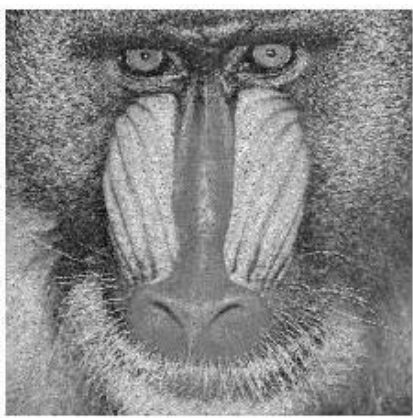

(f) Método Proposto

Figura 11: Comparação da imagem Babuíno restaurada com 50\% de ruído pelos métodos. (a) Imagem original (b) Imagem com 50\% de ruído (c) FMP3x3 (d) FMP5x5 (e) FMC (f) Método proposto.

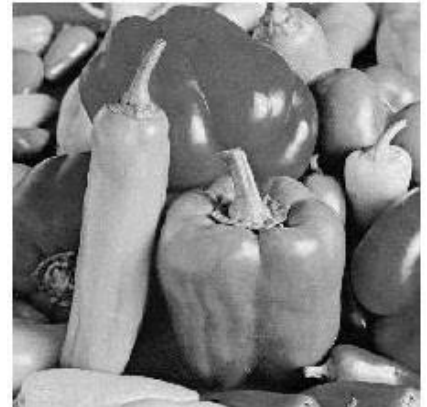

(a) Original

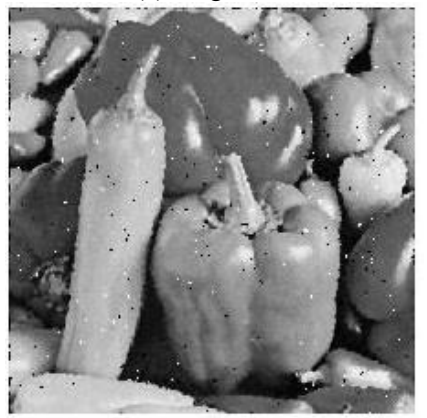

(d) FMP5x 5

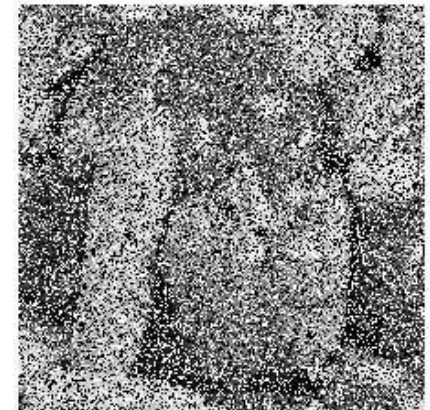

(b) Com Ruído

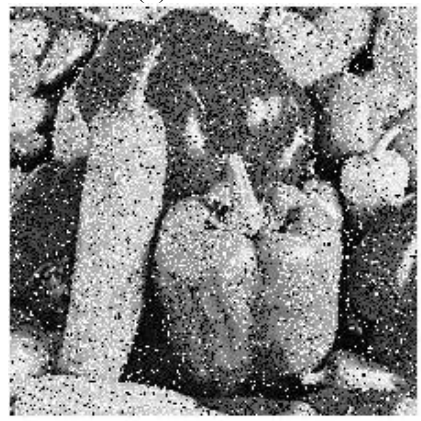

(e) FMC

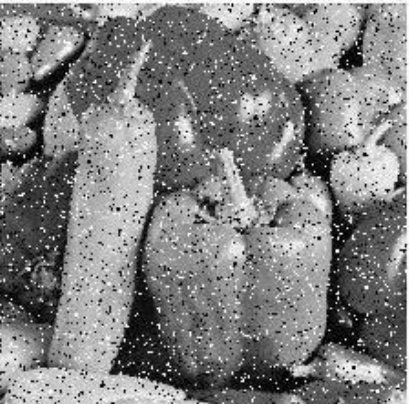

(c) FMP $3 \times 3$

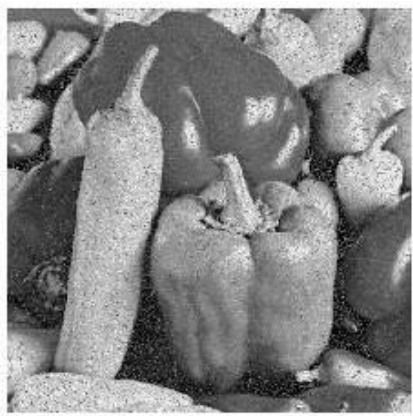

(f) Método Proposto

Figura 12: Comparação da imagem Pimentas restaurada com 50\% de ruído pelos métodos. (a) Imagem Original (b) Imagem com 50\% de ruído (c) FMP3x3 (d) FMP5x5 (e) FMC (f) Método Proposto.

O desempenho do método proposto também é validado por uma medida objetiva quantitativa, baseado Erro Médio Quadrático (Mean Square Error - MSE), utilizado como critério de comparação [17], [24]-[26]. A fórmula de validação, neste caso, é:

$$
M S E=\frac{\sum_{i=1}^{N} \sum_{j=1}^{M}(X(i, j)-Y(i, j))^{2}}{N \times M}
$$

Onde $X(i, j)$ é a imagem original, $Y(i, j)$ é a imagem recuperada, $N$ é o número de linha e $M$ é o número de colunas da imagem. Para essa análise as imagens Lena, Babuíno e Pimentas foram corrompidas com o ruído impulsivo, variando de $10 \%$ a $80 \%$. As imagens foram recuperadas pelos métodos tradicionais e o método proposto. Os valores de MSE são mostrados nas Tabelas 1, 2 e 3 para as imagens Lena, Babuíno e Pimentas respectivamente.

Analisando as Tabelas 1, 2 e 3, percebe-se que o método proposto obteve os menores resultados de MSE para as três imagens em todas as proporções de ruído. Para mostrar os resultados de forma mais clara, a Figura 13 mostra o gráfico da proporção de ruído em relação ao MSE obtidos pela recuperação da imagem Lena pelos métodos. 
Tabela 1: Comparação dos valores MSE obtidos pela restauração da imagem Lena

\begin{tabular}{lccccc}
\hline Ruído & Imagem ruidosa & FMP3x3 & FMP5x5 & FMC & Método Proposto \\
\hline $10 \%$ & 7093,62 & 114,44 & 214,95 & 1124,94 & 151,86 \\
$20 \%$ & 14685,6 & 316,9 & 290,02 & 2664,15 & 275,20 \\
$30 \%$ & 22281,2 & 1089,72 & 411,97 & 4578,73 & 361,42 \\
$40 \%$ & 29792,5 & 3245,37 & 597,17 & 7685,5 & 481,44 \\
$50 \%$ & 37296,4 & 7559,26 & 1230,41 & 12498,9 & 735,68 \\
$60 \%$ & 44949,9 & 15327 & 3572,7 & 20239,7 & 1326,74 \\
$70 \%$ & 52328,2 & 26090,5 & 10067,9 & 30469,6 & 2423,95 \\
$80 \%$ & 59870,9 & 40470,3 & 24451,7 & 43680 & 4603,31 \\
\hline
\end{tabular}

Tabela 2: Comparação dos valores MSE obtidos pela restauração da imagem Babuíno

\begin{tabular}{lccccc}
\hline Ruído & Imagem ruidosa & FMP3x3 & FMP5x5 & FMC & Método Proposto \\
\hline $10 \%$ & 6980,42 & 1218,15 & 2170,45 & 1603,13 & 245,02 \\
$20 \%$ & 15451,4 & 1591,37 & 2310,36 & 3561,56 & 482,78 \\
$30 \%$ & 21726,9 & 2562,1 & 2486,28 & 6080 & 699,86 \\
$40 \%$ & 29139 & 4941,6 & 2796,46 & 9728,1 & 947,37 \\
$50 \%$ & 36397,6 & 9165,96 & 3581,46 & 14857,2 & 1312,79 \\
$60 \%$ & 43744,5 & 16525,7 & 5914,13 & 22441,9 & 2995,17 \\
$70 \%$ & 51036,3 & 27123 & 12690,8 & 32415,3 & 2995,17 \\
$80 \%$ & 58272,9 & 40363,5 & 25629,6 & 44301,3 & 4829,24 \\
\hline
\end{tabular}

Tabela 3: Comparação dos valores MSE obtidos pela restauração da imagem Pimentas

\begin{tabular}{cccccc}
\hline Ruído & Imagem ruidosa & FMP3x3 & FMP5x5 & FMC & Método Proposto \\
\hline $10 \%$ & 7559,59 & 251,09 & 307,01 & 1221,44 & 244,75 \\
$20 \%$ & 15554,4 & 489,84 & 381,07 & 3671,44 & 444,20 \\
$30 \%$ & 23339,3 & 1321,48 & 479,36 & 4649,65 & 625,18 \\
$40 \%$ & 31479,4 & 3600,27 & 698,46 & 7836,82 & 894,42 \\
$50 \%$ & 39318,7 & 8228,58 & 1355,55 & 12980,6 & 1375,28 \\
$60 \%$ & 47454,6 & 16366,6 & 3969,64 & 21125,1 & 2298,46 \\
$70 \%$ & 55161,1 & 27723,2 & 10806,1 & 31923,9 & 3920,67 \\
$80 \%$ & 63205,6 & 42807,5 & 26174,9 & 45929,7 & 6806,96 \\
\hline
\end{tabular}

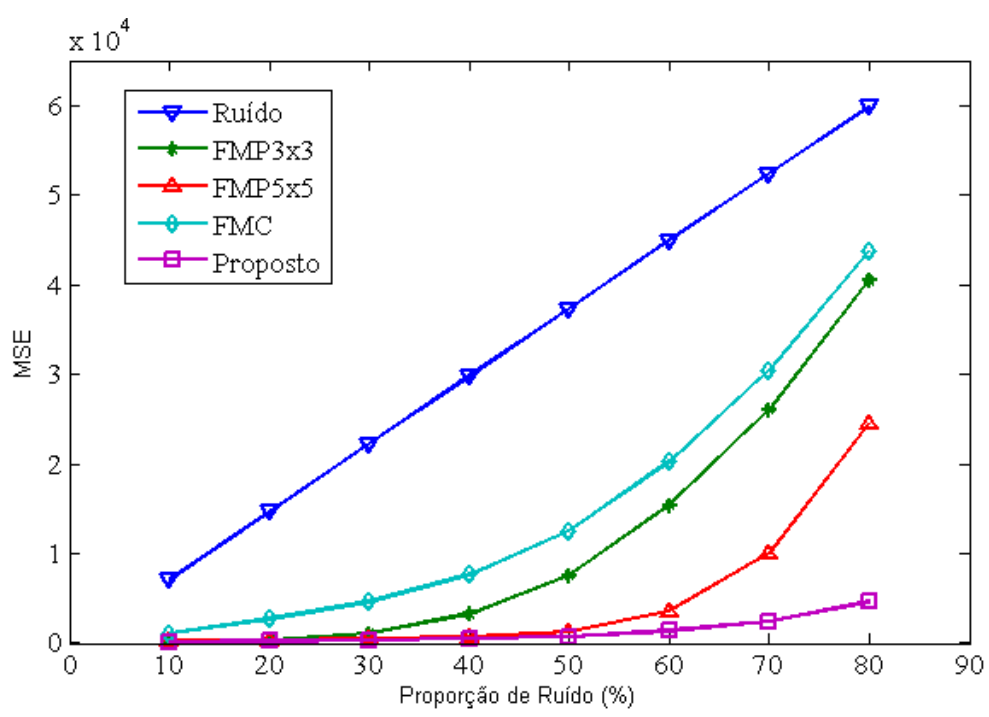

Figura 13: Comparação do desempenho dos métodos em relação ao ruído impulsivo para a imagem Lena 
Uma medida que deve ser considerada para algoritmos de recuperação de imagens é o tempo computacional. O treinamento da RNA-1 obteve tempo computacional de $18 \mathrm{~s}$, tendo em vista que seu treinamento foi feito com imagens artificiais de ordem cem. Já a RNA-2 utilizando imagens reais da ordem de 256 obteve o tempo computacional de 229s para o treinamento.

Os algoritmos dos métodos mencionados foram implementados em um processador Intel Core ${ }^{\mathrm{TM}}$ i5 $2,67 \mathrm{GHz}$ com 4 GB de RAM usando o MATLAB ${ }^{\circledR}$ 7.11. Para cada método, a imagem Lena foi apresentada com proporções de ruído $10 \%-80 \%$. Em cada proporção de ruído, vinte execuções foram realizadas, tendo cada método o objetivo de realçar a imagem. O tempo computacional em segundos (s) foi calculado para cada execução, e em seguida a média aritmética foi calculada para obter o valor do tempo computacional de cada método. Os valores obtidos pelos métodos podem ser observados na Tabela 4.

Os métodos citados para redução de ruído são métodos diretos, ou seja, executam uma sequência de passos até terminar sua execução, que é reduzir o ruído. Já para o método proposto é necessário ocorrer mais uma etapa além da execução de remoção de ruído, que é o processo de treinamento da rede. Com essa etapa a mais para ser comprida pelo método proposto, a complexidade tende a ser maior em comparação com os outros métodos citados. Alisando a Tabela 4, percebe-se que o método proposto não conseguiu atingir os valores do método FMP3x3. No entanto, essa diferença pode ser descartada, tendo em vista que o método proposto apresentou melhores resultados numéricos e visuais.

Tabela 4: Comparação do tempo computacional obtido pela restauração da imagem Lena

\begin{tabular}{c|cccc}
\hline Proporção & \multicolumn{4}{|c}{ Tempo Computacional (s) } \\
\cline { 2 - 5 } Ruído & FMP3x3 & FMP5x5 & FMC & Método Proposto \\
\hline $10 \%$ & 1,295 & 1,993 & 1,806 & 1,680 \\
$20 \%$ & 1,306 & 2,004 & 2,005 & 1,708 \\
$30 \%$ & 1,294 & 1,993 & 2,225 & 1,764 \\
$40 \%$ & 1,296 & 2,000 & 2,464 & 1,748 \\
$50 \%$ & 1,300 & 1,997 & 3,015 & 1,778 \\
$60 \%$ & 1,302 & 2,005 & 3,197 & 1,802 \\
$70 \%$ & 1,315 & 2,074 & 3,666 & 1,837 \\
$80 \%$ & 1,311 & 2,156 & 3,961 & 1,952 \\
\hline
\end{tabular}

\section{Conclusões}

Neste trabalho apresentou-se um novo método baseado em duas redes neurais para detecção e redução de ruído impulsivo de imagens digitais. Os resultados do método foram comparados com outros métodos da literatura usando uma medida numérica baseada no MSE, observações visuais e tempo computacional. As vantagens do método podem ser assim resumidas:

1) o treinamento da RNA-1 é facilmente obtido usando imagens artificiais geradas por computador. A RNA-2 pode ser usada como um filtro eficiente para qualquer densidade de ruído impulsivo;

2) um melhor desempenho pode ser obtido por repetir o treinamento das RNAs do método proposto em imagens corrompidas. Por outro lado, a complexidade computacional do método proposto é maior do que os outros métodos encontrados na literatura. Isso se deve à necessidade de treinamento das RNAs, sendo uma propriedade inerente às redes neurais. No entanto, o treinamento das redes é executado até que se obtenha a configuração e arquitetura ideal para o problema. Uma vez treinadas, os parâmetros são fixados e o tempo de execução da rede se assemelha ao tempo dos algoritmos da literatura.

3) do ponto de vista científico, considerando a potencialidade e a versatilidade do método aqui aplicado, principalmente através da aplicação conjunta de duas RNAs, pode-se considerar que o método apresentando permite simular e analisar características importantes para redução de ruído impulsivo (sal e pimenta) presente em imagens digitais. Além disso, baseado em resultados preliminares, podemos considerar que o algoritmo backpropagation, usado nas simulações, apresenta um excelente desempenho para esse tipo de aplicação.

Os resultados obtidos através das simulações demonstram a viabilidade do método proposto, sobretudo pelas autoadaptações das RNAs, que têm como característica principal o reconhecimento de padrões. A RNA-1 conseguiu distinguir os pixels ruidosos dos normais, mantendo assim inalterados aqueles considerados normais, 
passando para a RNA-2 a tarefa de estimar os valores para os pixels ruidosos. Dessa forma, o método pode ser integrado a uma ferramenta que faça outros tipos de tratamento de imagens, como detecção de bordas. Para trabalhos futuros, os autores pretendem adaptar o método, para reconhecimento de outros tipos de ruídos, bem como pretendem analisar ruídos presentes em imagens sísmicas, como forma de reconhecer imagens de solo petrolífero.

\section{Agradecimentos}

Os autores agradecem à UFERSA, à CAPES e à FAPERN pelo apoio financeiro.

\section{Referências}

[1] PITAS, I.; VENETSANOPOUlOS, A. N. Nonlinear Digital Filters: Principles and Applications. Boston, MA: Kluwer, 1990.

[2] SUN, T.; NUEVO, Y. “Detail-preserving median based filters in image processing” Pattern Recognit. Lett., v. 15, p. 341-347, Apr. 1994.

[3] KO, S. J.; LEE, Y. H. "Center weighted median filters and their applications to image enhancement" IEEE Trans. Circuits Syst., v. 38, no. 9, p. 984-993, Sep. 1991.

[4] HARDIE, R. C.; BARNER, K. E. "Rank conditioned rank selection filters for signal restoration," IEEE Trans. Image Process., v. 3, no. 2, p.192-206, Mar. 1994.

[5] LIN, H.; WILSON, A. N. "Median filter with adaptive length" IEEE Trans. Circuits Syst., v. 35, no. 6, p. 675-690, Jun. 1988.

[6] ABREU, E.; LIGHTSTONE, M.; MITRA, S. K.; ARAKAWA, K. "A new efficient approach for the removal of impulse noise from highly corrupted images," IEEE Trans. Image Process., v. 5, no. 6, pp. 1012-1025, Jun. 1996.

[7] HWANG, H.; HADDAD, R. A. "Adaptive median filters: Newalgorithms and results," IEEE Trans. Signal Process., v. 4, no. 4, pp. 499-502, Apr. 1995.

[8] CHEN, T.; MA, K.; CHEN, L. “Tri-state median filter for image denoising,” IEEE Trans. Image Process., v. 8, no. 12, p. 1834-1838, Dec. 1999.

[9] ZHANG, D.; WANG, Z. "Impulse noise detection and removal using fuzzy techniques” Electron. Lett., v. 33, no. 5, p. 378-379, 1997.

[10] ZHANG, S.; KARIM, M. A. "A new impulse detector for switching median filters," IEEE Signal Process. Lett., v. 9, no. 11, pp. 360-363, Nov. 2002

[11] GARNETT, R.; HUEGERICH, T; CHUI, C. A Universal Noise Removal Algorithm with an Impulse Detector, IEEE Trans. Image Processing. v. 14, pp. 1747-1754, Nov. 2005.

[12] KALIRAJ, G.;BASKAR, S. An efficient approach for the removal of impulse noise from the corrupted image using neural network based impulse detector, Image and Vision Computing, v. 28, no. 3, p. 458-466, Mar. 2010.

[13] GABBOUJ, M.; COYLE, E. J.; GALLAGER, N. C. "An overview of median and stack filtering”, Circuit Syst. and Signal Processing, v. 11, no. 1, p. 7-45, 1992. 
[14] KARIM, S. Z. A New Impulse Detector for Switching Median Filters, Signal Processing Letters, IEEE, v. 9 , no. 11, p. 360-363, Nov. 2002.

[15] MARQUES FILHO, O; VIEIRA NETO, H. Processamento Digital de Imagens, Rio de Janeiro: Brasport, 1999.

[16] GONZALEZ, R. C.; WOODS, R. E. Digital Image Processing, Prentice-Hall, Englewood Cliffs, NJ, 2002.

[17] YÜKSEL, M. E. A hybrid neuro-fuzzy filter for edge preserving restoration of images corrupted by impulse noise, IEEE Trans. Image Process. v. 15, no. 4, pp. 928-936, Apr. 2006.

[18] CHEN, T.; WU, H. R. "Adaptive impulse detection using center weighted median filters", IEEE Signal Proc. Letters, v. 8, no. 1, pp. 1- 3, 2001.

[19] YLI-HARJA, O.; ASTOLA, J.; NEUVO, Y. "Analysis of the properties of median and weighted median filters using threshold logic and stack filter representation", IEEE Trans. on Signal Proc, v. 39, no. 2, pp. 395-410, 1991.

[20] YILDIRIM, M.T.; BASTURK, A.; YÜKSEL, M. E. “A Detail-Preserving Type-2 Fuzzy Logic Filter for Impulse Noise Removal from Digital Images", Fuzzy Systems Conference IEEE, London, pp. 1-6, 23-26 July. 2007.

[21] YÜKSEL, M. E.; BASTÜRK, A. "Efficient removal of impulse noise from highly corrupted digital images by a simple neuro-fuzzy operator”, AEU Internat. J. Electron. Comm, v. 57, no. 3, pp. 214-219, 2003.

[22] REZVANIAN, A.; FAEZ, K.; MAHMOUDI, F. A Two-Pass Method to Impulse Noise Reduction from Digital Images Based on Neural Networks, International Conference on Electrical and Computer Engineering - (ICECE), Dhaka, pp. 400-405, 20-22 Dec. 2008.

[23] THE USC-SIPI image database, University of Southern California [Online]. Disponível em: $<\mathrm{http}: / /$ sipi.usc.edu/services/database/Database.html> Acesso em: 30 Mar. 2012.

[24] BEŞDOK, E.; ÇIVICIOĞLU, P.; ALÇI, M. "Using an adaptive neurofuzzy inference system-based interpolant for impulsive noise suppression from highly distorted images", Fuzzy Sets and Systems, v. 150, no. 3, p. 525-543. Mar. 2005.

[25] YUAN, S. Q.; TAN, Y. H. "Impulse noise removal by a globallocal noise detector and adaptive median filter". Signal Proc, v. 86, no. 8, pp. 2123-2128. 2006.

[26] SMOLKA, B.; CHYDZINSKI, A. "Fast detection and impulsive noise removal in color images", RealTime Imaging, v. 11, no. 4, p. 389- 402. 2005. 